\title{
Mobile Phone Addiction and Loneliness among Teenagers
}

\author{
Dr. Mrunal Bhardwaj ${ }^{1}$, Miss. Sode Jaimala Ashok ${ }^{2}$
}

\section{ABSTRACT:}

The aim of this study is to analyse mobile phone addiction \& loneliness among. Survey research is used for this study. To collect data; personal information form, mobile phone addiction scale, and -loneliness scale were applied for 40 students who are from different colleges in Mumbai city. To analyze these data; correlation, $t$ test were calculated. Results revealed that mobile phone addiction was significantly associated with loneliness ( $\mathrm{r}=.456)$ Furthermore, no significant gender differences were found in terms of loneliness and mobile phone addiction.

Keywords: Mobile phone addiction, Loneliness, teenagers

\section{MOBILE PHONE ADDICTION}

As we all know there has been great development in technology. This has resulted in invention of many gadgets and cell phone is one of them. Despite its usefulness, excessive use of this device has various negative impacts. A person suffering from such a phenomenon is referred to as a cell phone addict. He relies over his cell phone for all the various day to day activities not concentrating on anyone else near him. A person is suffering from this form of addiction can be predicted by the cell phone bills and the abrupt behavior in case the cell phone is missing.

In addition to being a means of communication and having rapidly spreading use around the world, mobile phones, in particular the new generation of smart mobile phones, are technological tools due to offering many functions, such as providing short message service (SMS) to users, taking photos, playing games, using the Internet, connecting to social networks, providing navigation services, having a video player functionality, watching TV and shopping. Cell phone activities examined in the study included calling, texting, emailing, surfing the Internet, banking, taking photos, playing games, reading books, using a calendar, using a clock and a number of applications, among them the Bible, iPod, coupons, Google Maps, eBay, Amazon, Facebook, Twitter, Pinterest, Instagram, YouTube, iTunes, Pandora and "other" (news, weather, sports, lifestyle-related applications and Snapchat.)

\footnotetext{
${ }^{1}$ Vice- Principal. \& HOD PG Dept. of psychology, M. G. V'S. Loknete Vyankatrao Hiray College, Panchavati, Nashik-422003. Maharashtra

${ }^{2}$ Assistant Professor, PG Deptt of psychology, M. G. V's. Loknete Vyankatrao Hiray College, Panchavati, Nashik
} 
They also remarked that students have taken quite a lot of time to use their mobile phones. Considering the facilities that a mobile phone provides to individuals as mentioned above, these facilities can be handled at the same time as the needs of individuals. While normal use of mobile phones is to restrict individuals' use of mobile phones in accordance with their needs, problematic use of mobile phones occurs due to the fact that individuals aren't able to restrict their use in accordance with the needs. The findings of some studies have indicated that problematic use of mobile phones has negative effects.. Ha, Chin, Park, Ryuve Yu (2008) found that the excessive user group experienced more depressive symptoms, difficulty in expression of emotion than the comparison group did.

Considering the features of mobile phones, especially smart mobile phones, recently introduced, it is seen that these kinds of mobile phones are not only manufactured to provide communication. These mobile phones include many features presented by the Internet and computers. In this context mobile phones offer a great opportunity, especially for young people who use the Internet. Individuals who have such a great opportunity can interact with mobile phones almost everywhere (at home, at school, on the bus, on the street, in the café, in the canteen, in bed, or even in the toilet). Individuals who have engaged in mobile phones constantly may be exposed to a decrease in the time allocated to other social relations, especially relations based on face-toface interaction. This situation may also make individuals lonely. Although mobile phones and the Internet are used as communication tools, excessive use of these technological tools causes individuals to become addicted. Even communication tools may cause non-communication situations. Individuals who are under these circumstances can be supported to receive the help of individual or group counseling in order to make use of such technological tools in accordance with their needs.

\section{LONELINESS}

Loneliness is one of the most common feelings that individuals could experience in their lives. Loneliness is a negativeemotion that comes about through a discrepancy between desired and achieved levels of social contact (Perlman \&Peplau,1981). According to Lopata (1969), loneliness is an emotion experienced by an individual who wishes for a level of contact unlike from the one currently encountered. The multiplicity of social relations does not matter but the quality of them isimportant. However, having more social relations may not always derive individuals a profit in social life.

While common definitions of loneliness describe it as a state of solitude or being alone, loneliness is actually a state of mind. Loneliness causes people to feel empty, alone and unwanted. People who are lonely often crave human contact, but their state of mind makes it more difficult to form connections with other people.

The most broadly accepted definition of loneliness is the distress that results from discrepancies between ideal and perceived social relationships. This so-called cognitive discrepancy perspective makes it clear that loneliness is not synonymous with being alone, nor does being 
with others guarantee protection from feelings of loneliness. Rather, loneliness is the distressing feeling that occurs when one's social relationships are perceived as being less satisfying than what is desired. This entry describes how loneliness is conceived and measured how loneliness is mentally represented; how loneliness influences thoughts, feelings, and behaviors; and consequences of loneliness for health and wellbeing.

Mobile phones offer many possibilities presented by the Internet and computers. While computers and the Internet may cause loneliness of individuals, may mobile phone cause loneliness of individuals? In this context the purpose of the study is to examine loneliness of college students in terms of daily use of mobile phone, mobile phone addiction and gender. We therefore would expect that higher or problematic phone use is predicted by loneliness

\section{REVIEW OF LITERATURE}

When studies are analyzed on loneliness, it is seen that loneliness is associated with some variables. Loneliness is related to the variables of depression (Anderson, \&Arnoult, 1985; Brage,Meredith, \&Woodward, 1993; Ceyhan, \& Ceyhan, 2011; Nangle,Erdley, Newman, Mason, \& Carpenter, 2003; Rotenberg, \& Flood, 1999; Ünal, \& Bilge, 2005; Wang, Yuen, \& Slaney, 2009; Wei, Russell, \&Zakalik, 2005; Yaacob, Juhari,Talib,\&Uba, 2009), stress (Yaacob, Juhari,Talib,\&Uba, 2009).

In Arslan's (2013) study, the problematic phone use increases as talking time increases, however increase of talking time decreases loneliness level in teenagers. Jin and Park (2012) found that more face-to-face interactions were associated with lower levels of loneliness; however, more cell phone calling was associated with greater loneliness. Reidand Reid (2007) revealed that lonely people preferred calls and rated text such as short message service (SMS, or text messaging) as a less intimate method of contact. According to Takao, et al. (2009) it is conceivable that lonely people areeager to maintain contact with their peers through frequent calls so as to fulfill their loneliness Wei,\&Lo,2006).

Satoko Ezoe1, Masahiro (2013) investigated factors contributing to Internet addiction in 105 Japanese medical students. The subjects were administered by a self-reporting questionnaire designed to evaluate demographic factors, Internet addiction, loneliness, health- related lifestyle factors, depressive state, patterns of behavior, and mobile phone dependence. Results of multivariate logistic regression analysis indicated that loneliness and mobile phone dependence were positively related to degree of addiction. Their findings suggest that Internet addiction is associated with loneliness and mobile phone dependence in Japanese students.

Loneliness and Mobile Phone -, Mustafa analyzed loneliness of university students according to mobile phone addiction, daily phone use time and gender. Survey model has used for this research. To collect data; personal information form, problematic mobile phone use scale, and UCLA-loneliness scale were applied for 527 students who are from different Departments of Faculty of Education at Frat University. To analyze these data; correlation, $t$ test, one way variance (ANOVA) analysis and Scheffe test were used. Results revealed that loneliness was significantly associated with problematic mobile phone use $(\mathrm{r}=.35)$. 


\section{OBJECTIVES:}

1) To measure the mobile phone addiction among teenagers (Girls \& Boys).

2) To measure the loneliness among teenagers (Girls \& Boys).

3) To study the relationship between mobile phone addiction and loneliness among teenagers.

\section{HYPOTHESES}

1) There is a high level of mobile phone addiction among teenagers (Girls \& Boys).

2) There is no gender difference in term of mobile phone addiction.

3) There is a high level of loneliness among teenagers (Girls \& Boys).

4) There is no gender difference in term of loneliness.

5) There is a positive relationship between mobile phone addiction and loneliness among teenagers

\section{RESEARCH VARIABLES}

1) Gender

2) Mobile phone addiction

3) Loneliness

\section{CONTROLLED VARIABLES}

1) Age

2) Economic status

\section{RESEARCH DESIGN}

In this study an attempt has been made to find out the relation between mobile phone addiction and loneliness among teenagers. It is a survey research\& a correlation study.

\section{SAMPLE}

\begin{tabular}{|c|l|c|}
\hline 1) & GROUP & $\begin{array}{l}\text { No of } \\
\text { Sample }\end{array}$ \\
\hline 1 & Boys teenagers & $\mathbf{5 0}$ \\
\hline 2 & Girls teenagers & $\mathbf{5 0}$ \\
\hline
\end{tabular}

The sample

Total Sample $=\mathbf{1 0 0}$ was selected by
using random sampling Method. It consisted of 150 teenagers of Mumbai city in Maharashtra. The age range was 13-17 yrs . First they were administered with Mobile phone addiction scale. Finally 100 teenagers (50 Boys and 50 Girls) were selected who scored high on mobile phone addiction scale. Then second test of Loneliness was given to them.

\section{TOOLS:}

\section{1) MOBILE PHONE ADDICTION SCALE (2012)}

Mobile phone addiction scale by Dr. A. Velayudhan \& Dr. S. Srividya was used to measure the mobile phone addiction.. It contains 37 items used five point response format it is five point Likert scale. It contains six subscales 1) Maladaptive Usage 2) Self Expression 3) Peer 
Relationship \& Mobile Phone 4) Interpersonal Relationship 5) Impulsivity 6) Usage Time. The score of the scale ranged from 37-245. The higher the score higher the mobile phone addiction.

\section{RELIABILITY}

The alpha (test retest) reliability of the scale was found to 0.79 and the split half reliability index was found to be 0.75 . The internal consistency reliability was found to be 0.89 .

\section{VALIDITY:}

The content item and concurrent validity of the test is high.

2) LONELINESS INVENTORY (2010)

Loneliness Inventory by Uma, Meenakshi. R. \& Prof. K. Krishnan was used to measure the loneliness . It contains 19 items used five point response format it is five point Likert scale.

\section{RELIABILITY}

The Pearson's product moment correlation coefficient is 0.72 . The reliability coefficient is significantly high.

\section{VALIDITY:}

The content item and concurrent validity of the test is high.

\section{RESULTS}

The purpose of the study was to measure the mobile phone addiction and loneliness among teenagers. Here t-test statistic was applied to check the significant difference in mobile phone addiction and loneliness among teenagers.

Co - relational method is used for determining the relation between mobile phone addiction and loneliness.

TABLE NO - 1, Table No 1.1 showing the means \& $t$ value in terms of Mobile phone addiction.

\begin{tabular}{|l|l|c|c|c|c|c|c|}
\hline \multicolumn{1}{|c|}{ Test } & \multicolumn{1}{|c|}{ Group } & N & Mean & SD & SED & t & Sign \\
\hline \multirow{2}{*}{$\begin{array}{l}\text { Mobile Phone } \\
\text { Addiction }\end{array}$} & Boys (teenagers) & 50 & 144.4 & 15.3 & 4.56 & 1.16 & NS \\
\cline { 2 - 6 } & Girls (teenagers) & 50 & 142.9 & 13.3 & & & \\
\hline
\end{tabular}

Table 1 shows the difference in Mobile Phone Addiction among teenagers for Mobile Phone Addiction scale the obtained values for boys Mean $(M)=144.4 \&$ Standard Deviation (SD) $=15.3$ and in comparison with the girls' Mean $(M)=142.9$ and Standard Deviation (SD) =13.3. The obtained $\mathrm{t}$ value is 1.16 which is not significant. This indicates that there is no signification gender difference associated with mobile phone addiction, it is indicative that in a changing scenario societal norms are changing so boys and girls are equally using mobiles and social networking. 
TABLE NO-2, Table No 2 showing the means \& $t$ value in terms of loneliness.

\begin{tabular}{|r|l|c|c|c|c|c|c|}
\hline Test & Group & $\mathrm{N}$ & Mean & SD & SED & $\mathrm{t}$ & Sign \\
\hline \multirow{2}{*}{ Loneliness } & Boys teenagers & 50 & 68.45 & 9.15 & 1.86 & 1.56 & NS \\
\cline { 2 - 8 } & Girls teenagers & 50 & 67.85 & 8.94 & & & \\
\hline
\end{tabular}

Table 1 shows the difference in loneliness among teenagers, the obtained values for boys are Mean $(M)=68.45 \&$ Standard Deviation $(S D)=9.15$ and in comparison with the girls Mean (M) $=67.85$ and Standard Deviation $($ SD) $=8.94$. The obtained t value is 1.56 which is not significant so the level of loneliness is equal irrespective of gender.

Table No -3

\begin{tabular}{|c|c|c|c|}
\hline Test & Mean & SD & N \\
\hline Mobile Phone Addiction & 144.20 & 13.255 & 100 \\
\hline Loneliness & 63.08 & 7.774 & 100 \\
\hline
\end{tabular}

Table N0 - 4, Table No 4 showing the relationship between mobile phone addiction and loneliness

\begin{tabular}{|l|l|r|r|}
\hline & & MPA & $\begin{array}{c}\text { Lonelines } \\
\mathrm{s}\end{array}$ \\
\hline $\begin{array}{l}\text { Mobile Phone } \\
\text { addiction }\end{array}$ & $\begin{array}{l}\text { Pearson } \\
\text { Correlation }\end{array}$ & 1 & $.554(* *)$ \\
& Sig. (2-tailed) &. & .003 \\
\hline & $\mathrm{N}$ & 100 & 100 \\
\hline \multirow{2}{*}{ Loneliness } & Pearson & $.554(* *)$ & 1 \\
& $\begin{array}{l}\text { Correlation } \\
\text { Sig. (2-tailed) }\end{array}$ & .003 &. \\
\hline & N & 100 & 100 \\
\hline
\end{tabular}

\section{** Correlation is significant at the 0.01 level (2-tailed).}

Table no 4 shows the correlation between mobile phone addiction \& loneliness among boys and girls, teenagers .For this analysis person correlation method was used. For the obtained value in table no 4 show the correlation score between mobile phone addiction and loneliness is.554 and it is significant at $\mathbf{0 . 0 1}$ level ( 2 tailed). This indicates that the correlation between mobile phone addiction and loneliness is positive. It indicates that higher the level of loneliness greater the mobile phone addiction. 


\section{DISCUSSION}

Mobile phone addiction and Loneliness among teenagers was examined in the current study. When literature is analyzed, the literature has revealed that studies on mobile phone addiction related to loneliness are quite a few. In this context, this study may be important for the literature.

The aim of the present study was to examine the mobile phone addiction \& loneliness among teenagers. The researcher selected the sample of 100 teenagers out of which, 50 were boys and 50 were girls.

When mobile phone addiction and loneliness among teenagers were examined according to gender, there was no significant difference found in the study. The results of some studies are similar to the results obtained from this study (Erözkan, 2004; Karaolu, Av arolu, \&Deniz, 2009; Wiseman, Guttfreund, \& Lurie, 1995).

Some studies also indicated that there were no significant differences between the loneliness scores of male and female students (Gürsoy, \&Bçakç, 2006; Sezer, Tekin, \&Aldemir, 2011). The results were supported by the studies of Kraut and his colleagues',. Kraut et al. (1998) which claimed that pathological use of the new technologies reduces the individual's social implication in the real world and, as a consequence, his or her psychological well-being, because it produces the kind of isolation, loneliness and depression the individual wants to ease by connecting to the Internet.

There was significant correlation found between the mobile phone addiction and loneliness among college students. The last hypothesis is also proved in the study.

Chen's (2006) result indicated heavy mobile phone users meet their friends less. Ha et al., (2008) found that the excessive user group experienced difficulty in expression of emotion than the comparison group did. Furthermore, excessive user group had higher interpersonal anxiety than the comparison group.

\section{CONCLUSIONS}

1) There is a high level of mobile phone addiction was found among teenagers.

2) There is no gender difference found in terms of mobile phone addiction.

3) There is a high level of loneliness was found among teenagers.

4) There is no gender difference found in terms of loneliness.

5) There is a significant correlation found between the mobile phone addiction and loneliness among college students.

\section{LIMITATIONS}

1) There was the limitation regarding the size of the sample. The sample size was limited.

2) The sample consisted of college students only from Mumbai city. 


\section{INTERVENTION STRTEGIES FOR MOBILE ADDICTION FOR PARENTS AND TEENAGERS}

- There is a need to regularly monitor the cell phone usage.

- Keep a track of the time that you spend talking and messaging. Note it down for reference later.

- Try using other things to serve your needs such as notepad to jot down anything and a watch for monitoring time.

- After finding the time spent over cell phone it is now required to reduce your dependence over it by slowly decreasing the time spent, this can be done by choosing the activity of less importance on the cell phone and reducing your dependence over phone for that particular activity.

- The major reason for cell phone usage is to be with any other person. The usage can be reduced if you be with that person instead of conversing over the cell phone. Focusing on the person conversing to you is also very important and in order to do this you should keep your cell phone away when carrying out one on one conversation, this is essential for retaining people's respect.

- There is a need to believe that exchanging messages continuously on your cell phone is not the only way to enhance and make your social contacts instead it unnecessarily increases your level of anxiety.

- Even checking your email every $10 \mathrm{~min}$ is not necessary except for certain important people with corporate links.

- Another thing that can be done is to turn off the cell phone at night as it is not necessary to be used while sleeping

- It is believed than the number of people suffering from this form of addiction is bound to increase greatly in future. Hence, there is a need for greater focus in this area by both the government and the people alike.

\section{REFERENCES}

Anderson, C. A., \& Arnoult, L. H. (1985). Attributional style and everyday problems in living Depression, loneliness, and shyness. Social Cognition, 3(1), 16-35.

Arslan, A., \& Ünal, A.T. (2013). Examination of cell phone usage habits and purposes of education faculty students. International Journal of Human Sciences, 10(1), 182-201.

Ba, G. (2010). An Investigation of the relationship between shyness and loneliness levels ofelementary students in a Turkish sample. International Online Journal of Educational Sciences, 2 (2), 419-440.

Bianchi, A., \& Phillips, J.G. (2005). Psychological predictors of problem mobile phone use. Cyber psychology \& Behavior, 8(1), 39-51

Brage, D., Meredith, W., \& Woodward, J. (1993). Correlates of loneliness among mid-western adolescents. Adolescence, 28(111), 685. 